\title{
MicroRNA-96 expression induced by low-dose cisplatin or doxorubicin regulates chemosensitivity, cell death and proliferation in gastric cancer SGC7901 cells by targeting FOXO1
}

\author{
CHUNHUI LANG ${ }^{1,2}$, MIAO XU ${ }^{1}$, ZIYI ZHAO ${ }^{3}$, JINYAO CHEN ${ }^{1}$ and LISHI ZHANG ${ }^{1}$ \\ ${ }^{1}$ Department of Nutrition, Food Safety and Toxicology, West China School of Public Health, \\ Sichuan University, Chengdu, Sichuan 610041; ${ }^{2}$ Department of Clinical Nutrition, \\ Chongqing Three Gorges Central Hospital, Wanzhou, Chongqing 404000; ${ }^{3}$ Central Laboratory, \\ The Teaching Hospital of Chengdu University of Traditional Chinese Medicine, Chengdu, Sichuan 610072, P.R. China
}

Received October 21, 2016; Accepted February 15, 2018

DOI: $10.3892 / \mathrm{ol} .2018 .9122$

\begin{abstract}
MicroRNA-96 (miR-96) is transcriptionally associated with the induction of chemoresistance following chemotherapy by targeting to FOXO1 mRNA at one of two predicted binding sites in its 3 -untranslated region sequence. The upregulation of miR-96 is associated with a high risk of chemoresistance. Nevertheless, the mechanism by which miR-96 is upregulated remains largely undefined. In the present study, the gastric cancer SGC7901 cell line was treated with different doses of the chemotherapeutic agents cisplatin and doxorubicin. miR-96 expression was analyzed by reverse transcription-quantitative polymerase chain reaction at different time points. Western blot and chromatin immunoprecipitation were performed to analyze the expression levels of the target gene. The effects of miR-96 on chemosensitivity were assessed by a carboxyfluorescein succinimidyl ester/propidium iodide labeling assay, and its effects on proliferation were assessed by Cell Counting Kit- 8 or EdU staining assays. The results demonstrated that treatment with a low dose of either chemotherapeutic agent induced miR-96 expression. Upregulation of miR-96 caused the post-transcriptional repression of FOXO1 expression. Decreases in FOXO1 protein levels led to a decrease in the transcriptional activity of the cyclin-dependent kinase inhibitor 1A (CDKN1A, also known as p21) promoter region, and thus the expression of p21 was downregulated in a tumor protein p53-independent manner. As a result, induction of miR-96 expression caused chemoresistance and promoted proliferation in SGC7901 cells. Taken
\end{abstract}

Correspondence to: Professor Lishi Zhang, Department of Nutrition, Food Safety and Toxicology, West China School of Public Health, Sichuan University, 16 South Renmin Road, Chengdu, Sichuan 610041, P.R. China

E-mail: lishizhang_56@163.com

Key words: microRNA-96, cisplatin, doxorubicin, chemosensitivity, cell death, proliferation, forkhead box protein O1, SGC7901 together, the results of the present study revealed that treatment with cisplatin or doxorubicin could induce expression of miR-96 at certain doses. Upregulation of miR-96 is partially associated with chemoresistance and miR-96 can also promote cell proliferation by repressing $\mathrm{p} 21$.

\section{Introduction}

MicroRNAs (miRNAs/miRs) are a novel class of non-coding RNAs that post-transcriptionally regulate gene expression via translational inhibition or direct degradation of the target RNAs (1). More than $30 \%$ of all mRNAs are predicted to be targeted by miRNAs (2). miRNAs can negatively or positively regulate not only the physiological processes, but also the critical pathways of carcinogenesis, including cellular proliferation, colony formation, apoptosis and migration (3).

Gastric cancer is one of the most prevalent human cancer types, and is particularly common in the Far East region, including China (4), and is the second-leading cause of global cancer-associated mortality. For the past few decades, surgical resection with chemoradiation has been used to improve the 1- and 5-year survival rates $(5,6)$. However, the majority of gastric cancer cases are not diagnosed until they reach advanced or metastatic stages, which markedly decreases the 1- and 5-year survival rates, owing to the increased chemoresistance of metastatic disease (7). Although novel chemotherapeutic agents have been used clinically, the median survival time remains $<1$ year (8). Thus, further research is required to investigate the mechanisms of chemoresistance reversal.

Recent studies have revealed data concerning the involvement of miRNAs in carcinogenesis and increases in chemoresistance. Among these miRNAs, miR-96 has recently been demonstrated to be involved in the invasive and metastatic potential of several types of carcinoma, including hepatocellular carcinoma (9), breast cancer (10), lung cancer (11), pancreatic cancer (12) and bladder cancer (13). One previous report has indicated that miR-96 has a notable role in the induction of chemoresistance (14). In non-small cell lung cancer cells, miR-96 was found to be a critical 
inducer of cisplatin chemoresistance (14). In breast cancer, miR-96 was markedly upregulated in breast cancer cells and tissues following chemotherapy (15). The wide involvement of miR-96 promoted a focus on the association of this miRNA with chemoresistance in gastric cancer.

In the current study, the expression of miR-96 in gastric cancer cells following chemotherapeutic treatment was quantified at different doses and time points to assess its expression pattern under different conditions. It was determined that miR-96 expression was likely to be promoted by chemotherapeutic treatment and thus decreases the expression level of forkhead box protein O1 (FOXO1) by targeting FOXO1 miRNA directly, which is consistent with one previous report demonstrating that miR-96 post-transcriptionally regulates FOXO1 (16). This reduced the expression of cyclin-dependent kinase inhibitor 1A (CDK1A, also known as p21), without disturbing that of tumor protein P53 (hereafter p53).

\section{Materials and methods}

Cell culture. The human gastric carcinoma SGC7901 cell line (Type Culture Collection of the Chinese Academy of Sciences, Shanghai, China) was used in the present study. Cells were cultured in RPMI-1640 medium (Life Technologies; Thermo Fisher Scientific Inc., Waltham, MA, USA) supplemented with $10 \%$ fetal bovine serum (FBS; Life Technologies; Thermo Fisher Scientific Inc.) at $37^{\circ} \mathrm{C}$ in an incubator with $5 \% \mathrm{CO}_{2}$.

miRNA mimics and short hairpin RNA (shRNA) cell transfection. miRNA mimics and modified antisense oligonucleotide (antago)-miRNA, with scrambled miRNA and scrambled antago-miRNA as negative controls respectively, were synthesized and purchased (Guangzhou RiboBio Co., Ltd., Guangzhou, China). Plasmids coding for shRNA targeting human FOXO1 and scrambled shRNA as negative control were purchased from Guangzhou RiboBio Co., Ltd. SGC7901 cells were seeded into six-well plates with a starting cell number of $1 \times 10^{5}$, without serum and antibiotics. miRNA mimics or antago-miRNA were transfected into cells at a concentration of $50 \mathrm{nmol} / 1$ using Lipofectamine RNAiMAX (Invitrogen; Thermo Fisher Scientific, Inc.) according to the manufacturer's protocol. For shRNA plasmid transfection, $0.8 \mu \mathrm{g}$ plasmid for each well was transfected into SGC7901 cells using Lipofectamine ${ }^{\circledR} 2000$ (Invitrogen; Thermo Fisher Scientific, Inc.) according to the manufacturer's protocol. After $6 \mathrm{~h}$ incubation, the medium were replaced with fresh medium containing $10 \%$ FBS. A total of $48 \mathrm{~h}$ later, all cells were harvested for further analysis.

Reverse transcription-quantitative polymerase chain reaction $(R T-q P C R)$. For quantitative measurement of target microRNAs, TaqMan microRNA assay kit containing specific primers; miR-96 forward, 5'-TTTGGCACTAGCACAT-3' and reverse, 5'-GAGCAGGCTGGAGAA-3'; Let-7a forward, 5'-TGAGGTAGTAGGTTGTGTGGTT-3' and reverse, 5'-GCT GTCAACGATACGCTACCTA-3'; miR-9 forward, 5'-GGT CCTGGATCCCATCTTTT-3' and reverse, 5'-GCGCAGTGT ATGGGGTTATT-3'; $\beta$-actin forward, 5'-CATGTACGTTGC TATCCAGGC-3' and reverse, 5'-CTCCTTAATGTCACGCAC GAT-3' (Applied Biosystems; Thermo Fisher Scientific, Inc.) were used for selected miRNAs, including miR-96, Let-7a and miR-9, in accordance with the manufacturer's protocol. Let-7a and miR-9 were used as negative controls, as their expression levels are constant during chemotherapy (17). $\beta$-actin was used as reference. In brief, total RNA was isolated from the target cells using a mirVana miRNA Isolation kit (Ambion; Thermo Fisher Scientific, Inc.). A total of $100 \mathrm{ng}$ total RNA was used as template in each reaction with miRNA-specific RT primers. The reaction was incubated for $30 \mathrm{~min}$ at $37^{\circ} \mathrm{C}$. Next, the cDNA was used as a template following the qPCR instructions. Thermocycling conditions were as follows: $20 \mathrm{sec}$ at $95^{\circ} \mathrm{C}$ (enzyme activation), and 40 cycles of $5 \mathrm{sec}$ at $95^{\circ} \mathrm{C}$ (denaturation) and $30 \mathrm{sec}$ at $60^{\circ} \mathrm{C}$ (annealing and extension). For data analysis, the $2^{-\Delta \Delta \mathrm{Cq}}$ method was performed (18).

EdU staining. An EdU detection kit (Guangzhou RiboBio Co., Ltd.) was used according to the manufacturer's protocol. A total of $1 \times 10^{6}$ SGC7901 cells were incubated with $50 \mu \mathrm{M}$ EdU labeling medium (provided with the kit) at $37^{\circ} \mathrm{C}$ for $2 \mathrm{~h}$. Following immobilization, staining with Apollo ${ }^{\circledR} 567$ solution (provided with the kit) for $30 \mathrm{~min}$ at $37^{\circ} \mathrm{C}$ and Hoechst 33342 solution (provided with the kit) for $30 \mathrm{~min}$ at $37^{\circ} \mathrm{C}$, cells were imaged under a X71 (U-RFL-T) fluorescence microscope (Olympus Corporation, Tokyo, Japana).

Western blot analysis. Cells were lysed using Cell Lysis buffer (Beyotime Institute of Biotechnology, Shanghai, China) that contained $1 \mathrm{mM}$ phenylmethylsulfonyl fluoride and $1 \mathrm{X}$ protease inhibitors cocktail (Roche Applied Science, Penzberg, Germany). Following quantification using a bicinchoninic acid assay kit (Sigma-Aldrich, Merck KGaA, Darmstadt, Germany), a total of $20 \mu \mathrm{g}$ protein were subjected to $10 \%$ SDS-PAGE on $10 \%$ polyacrylamide gel. The resolved proteins were transferred onto a polyvinylidene difluoride membrane (EMD Millipore, Billerica, MA, USA), which was then blocked with $5 \%$ non-fat dried milk in TBS-Tween-20 buffer $(0.1 \%)$ for $1 \mathrm{~h}$ at room temperature prior to incubation overnight at $4^{\circ} \mathrm{C}$ with primary antibodies. Rabbit polyclonal antibodies against human FOXO1 (cat no. ab39670), p21 (cat no. ab129520), p53 (cat no. ab131442) and $\beta$-actin (cat no. ab8227) were obtained from Abcam (Cambridge, UK) at a dilution of 1:2,000. The membrane was then washed three times with TBS containing $0.05 \%$ Tween-20 prior to incubation for $1 \mathrm{~h}$ at room temperature with horseradish peroxidase-conjugated goat anti-rabbit antibodies IgG H\&L (Abcam; cat no. ab6721) at a dilution of 1:5,000. Immune complexes were detected with chemiluminescence reagents (EMD Millipore, MA, USA).

Chromatin immunoprecipitation (ChIP). The ChIP kit (Upstate Biotechnology, Inc., Lake Placid, NY, USA) was used to conduct the ChIP assay. A total of $1 \mu \mathrm{g} / \mathrm{ml}$ cisplatin with or without $10 \mu \mathrm{M}$ pifithrin- $\alpha$ (PFT- $\alpha$ ) was added to regular medium for $24 \mathrm{~h}$ incubation. Then, $2 \times 10^{6}$ cells were fixed with $1 \%$ formaldehyde for $15 \mathrm{~min}$ at room temperature and quenched by adding glycine at final concentration of $125 \mathrm{mM}$. Cell pellets were resuspended in SDS lysis buffer (Guangzhou RiboBio Co., Ltd.) for a further $10 \mathrm{~min}$ incubation at room temperature. The sheared DNA using sonication was diluted 10-fold in ChIP dilution buffer (Guangzhou RiboBio Co., Ltd.) and incubated with the FOXO1 antibody (Abcam; cat no. 39670) 
at final concentration of $100 \mathrm{ng} / \mu \mathrm{l}(1: 1,000), 4^{\circ} \mathrm{C}$ with rocking for $12 \mathrm{~h}$. Following the elution and reverse-crosslinking step, the eluent was used for qPCR using the SYBR ${ }^{\circledR}$ Premix Ex TaqTM kit (Takara Biotechnology Co., Ltd., Dalian, China) with the following primers: p21 promoter region forward, 5'-CCTTTCTATCAGCCCCAGAGGATACC-3' and reverse, 5'-GGGACGTCCTTA ATTATCTGGGGTC-3'; DHFR 3' untranslated region forward, 5'-CTGATGTCCAGGAGG AGAAAGG-3' and reverse, 5'-AGCCCGACAATGTCAAGG ACTG-3'; $\beta$-actin forward, 5'-CATGTACGTTGCTATCCA GGC-3' and reverse, 5'-CTCCTTAATGTCACGCACGAT-3', $\beta$-actin was used as reference. Thermocycling conditions were as follows: $20 \mathrm{sec}$ at $95^{\circ} \mathrm{C}$ (enzyme activation), followed by 40 cycles of $5 \mathrm{sec}$ at $95^{\circ} \mathrm{C}$ (denaturation) and $30 \mathrm{sec}$ at $60^{\circ} \mathrm{C}$ (annealing and extension). The data was analyzed using the $2^{-\Delta \Delta \mathrm{Cq}}$ method (18).

Cell death rate assay. Cell death caused by chemotherapeutic treatment $(1 \mu \mathrm{g} / \mathrm{ml}$ cisplatin or $1 \mu \mathrm{mol} / 1$ doxorubicin co-incubation for $24 \mathrm{~h}$ ) was tested for lytic activities using a carboxyfluorescein succinimidyl ester (CFSE)/propidium iodide (PI) labeling assay. Prior to chemotreatment, cells were labeled with $5 \mu \mathrm{M}$ CFSE (Sigma-Aldrich; Merck KGaA) for $10 \mathrm{~min}$ at $37^{\circ} \mathrm{C}$ in PBS. This process was halted by changing the supernatant for fresh medium containing chemoagent as indicated $(1 \mu \mathrm{g} / \mathrm{ml}$ cisplatin or $1 \mu \mathrm{mol} / 1$ doxorubicin). Following chemotherapeutic treatment, cells were incubated with $5 \mu \mathrm{g} / \mathrm{ml}$ PI (Sigma-Aldrich; Merck KGaA) at $37^{\circ} \mathrm{C}$ for $10 \mathrm{~min}$. To assess the cell death rate of SGC7901 cells following $1 \mu \mathrm{g} / \mathrm{ml}$ cisplatin or $1 \mu \mathrm{mol} / 1$ doxorubicin treatment after $24 \mathrm{~h}$, all cells were pre-stained with CFSE. After $24 \mathrm{~h}$, all cells were incubated with $5 \mu \mathrm{g} / \mathrm{ml} \mathrm{PI}$ at $37^{\circ} \mathrm{C}$ for $10 \mathrm{~min}$, and dead cells were positively stained.

Cell death rate analysis using flow cytometry. Cells were diluted into $1 \times 10^{6}$ cells $/ \mathrm{ml}$, fixed with ice-chilled $75 \%$ ethanol in $1 \mathrm{X}$ PBS overnight at $4^{\circ} \mathrm{C}$ and rinsed three times with PBS (5 min each). The cells were analyzed with a flow cytometer following staining with $1 \mathrm{ml} \mathrm{PI} \mathrm{(including} \mathrm{RNase)} \mathrm{for} 30 \mathrm{~min}$ at room temperature. The excitation wavelength $488 \mathrm{~nm}$ and the wavelength of emitted light was $>630 \mathrm{~nm}$. The software Cell Quest and Modfit LF (version 3.0; BD Biosciences, Franklin Lakes, NJ, USA) were used to assay the cell death rate of 10,000 cells.

Cell Counting Kit-8 (CCK-8) assay. Target cells were trypsinized, resuspended and seeded into 96 -well plate, each well with 5,000 cells. Cell viability was evaluated using Cell Counting kit-8 (Beyotime Institute of Biotechnology) according to the protocol of the manufacture at daily intervals on days 1-5 after seeding. Following treatment with CCK- 8 at $37^{\circ} \mathrm{C}$ for $1 \mathrm{~h}$, the absorbance was measured at $450 \mathrm{~nm}$ using a Multiskan spectrum microplate reader (Thermo Fisher Scientific, Inc.).

Statistical analysis. The data were expressed as the mean \pm standard deviation of three independent experiments. Statistical analyses were performed using IBM SPSS version 20 (IBM Corp., Armonk, NY, USA). Statistical comparisons were performed using unpaired Student's t-test for two-group comparisons of means. One-way analysis of variance with Dunnett's post hoc was used for comparisons of three or more groups. In all cases, $\mathrm{P}<0.05$ was considered to indicate a statistically significant difference.

\section{Results}

Low dose of chemotherapeutic agents treatment induces expression of miR-96 in gastric cancer cells. The gastric cancer SGC7901 cell line is frequently resistant to chemotherapeutic agents, including cisplatin and doxorubicin (19). Here, SGC7901 was treated with $1 \mu \mathrm{g} / \mathrm{ml}$ cisplatin or $1 \mu \mathrm{mol} / 1$ doxorubicin for $24 \mathrm{~h}$, and the expression level of miR-96 was detected by RT-qPCR. The results of this analysis revealed that treatment with chemotherapeutic agents significantly induced the expression of miR-96, but not Let-7a or miR-9 (Fig. 1A). Next, the effect of the two chemotherapeutic agents was assessed on miR-96 expression level at different time points $(24,48$ and $96 \mathrm{~h})$. It was observed that, compared with untreated cells, the miR-96 expression level at time points 24,48 and $96 \mathrm{~h}$ following treatment with chemotherapeutics were all higher, and miR-96 was expressed at a significantly higher level at $24 \mathrm{~h}$ (Fig. 1B). To determine the dose of chemotherapeutic agents that efficiently induced the expression of miR-96, the cells was treated with $1,2,5$ or $10 \mu \mathrm{g} / \mathrm{ml}$ cisplatin, or $1,2,5$ or $10 \mu \mathrm{mol} / 1$ doxorubicin respectively for $24 \mathrm{~h}$. A dose of $1 \mu \mathrm{g} / \mathrm{ml}$ cisplatin and $1 \mu \mathrm{mol} / \mathrm{l}$ doxorubicin induced miR-96 expression most efficiently, with a higher dose of either agent exhibiting no stronger an effect on miR-96 expression (Fig. 1C), indicating that the dose required to induce miR-96 expression is comparatively low.

Induction of miR-96 post-transcriptionally represses FOXOI expression and decreases the transcription of $p 21$. Identified as the direct target of miR-96, FOXO1 protein level is potentially regulated by miR-96 induced by chemotreatment (16). This promoted to identify whether miR-96 regulates FOXO1 expression in SGC7901 cells. Synthesized miR-96 mimics (miR-96), scrambled miR-96 mimics (scrambled), shRNA target to FOXO1 mRNA (shFOXO1), and scrambled shFOXO1 were introduced into SGC7901 for $48 \mathrm{~h}$. Western blot analysis was performed to detect FOXO1, GAPDH and $\beta$-actin protein levels. The results confirmed that miR-96 mimics exhibited similar effect on repressing FOXO1 protein level as treatment with shFOXO1 (Fig. 2A). Following treatment with cisplatin or doxorubicin, the FOXO1 protein level decreased significantly compared with the Mock group (Fig. 2B; right panel), whereas FOXO1 mRNA exhibited no observed changes (Fig. 2B; left panel). FOXO1 is reported to transcriptionally activate p21 in a p53-independent manner (20), with the results of the present study revealing that chemotreatment repressed p $21 \mathrm{mRNA}$ and protein expression levels without disturbing the p53 expression level (Fig. 2B). PFT- $\alpha$, which specifically inhibits transcription of p53, was pre-incubated with SGC7901 cells treated with $1 \mu \mathrm{g} / \mathrm{ml}$ cisplatin. As expected, inhibition of p53 exerted no additional effect on p21 mRNA expression level (Fig. 2C). To determine whether FOXO1 was involved in the regulation of p21 under treatment with chemotherapeutics, the binding of FOXO1 to p21 promoter region was assessed by ChIP. As expected, the binding of FOXO1 to p21 promoter decreased following treatment with chemotherapeutics (Fig. 2D). 
A

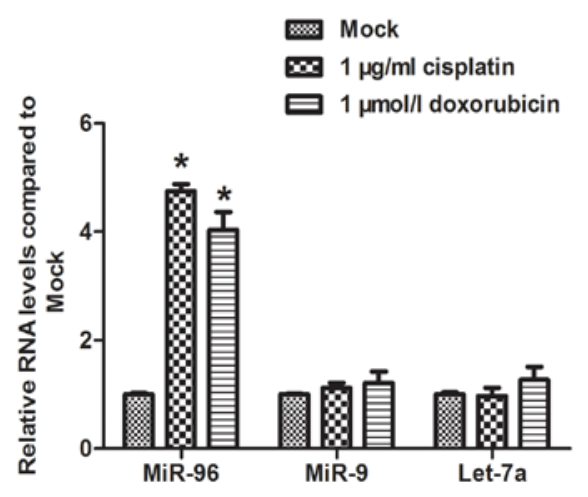

C

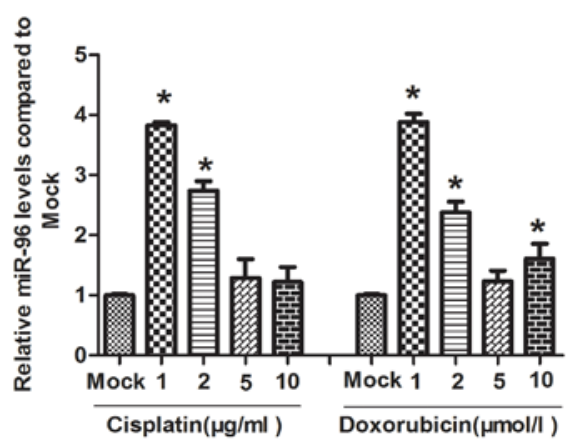

B

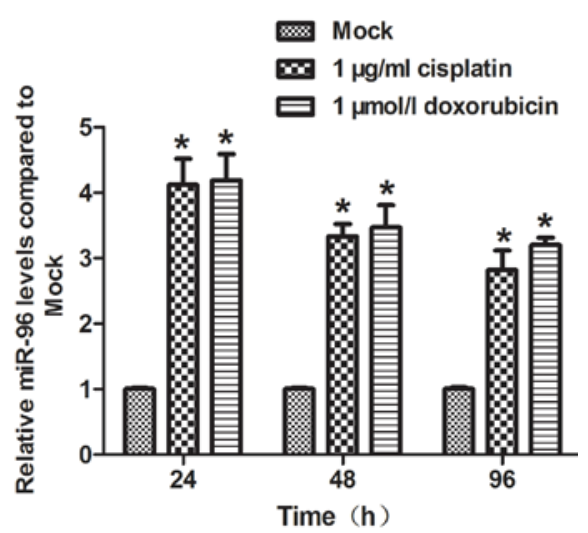

Figure 1. Chemotherapeutic treatment at low dose specifically induces the expression level of miR-96 in SGC7901 cells. (A) RT-qPCR analysis of SGC7901 cells treated with $1 \mu \mathrm{g} / \mathrm{ml}$ cisplatin or $1 \mu \mathrm{mol} / 1$ doxorubicin to detect the expression level of miR-96, Let-7a and miR-9. (B) To detect the effect of chemotherapeutic treatment on miR-96, cells chemotherapeutically treated for 24,48 and $96 \mathrm{~h}$ were analyzed by RT-qPCR for detecting the expression level of miR-96. (C) The effects of different doses of chemotherapeutic agent on miR-96 expression in SGC7901 cells. "P<0.05, compared with Mock. RT-qPCR, reverse transcription-quantitative polymerase chain reaction; miR-96, microRNA-96.

A
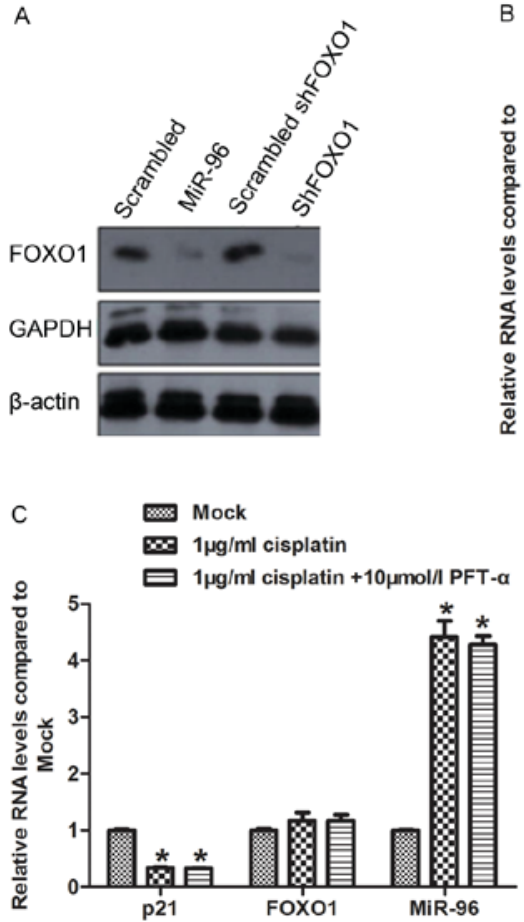

B

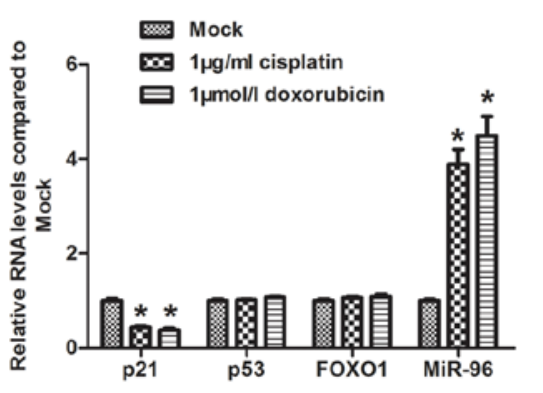

D

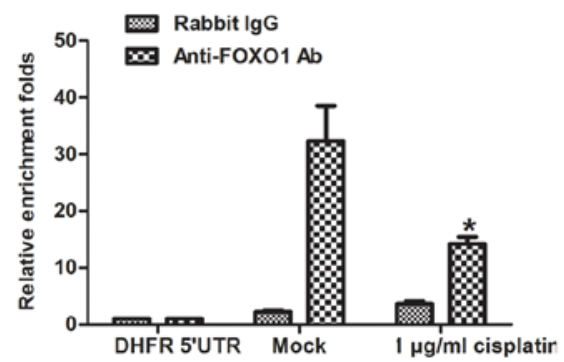

Figure 2. miR-96 expression post-transcriptionally regulates FOXO1 and thus modulates the expression of p21. (A) Protein levels of FOXO1 in SGC7901 cells transfected with miR-96 mimics or scrambled mimic negative controls. (B) To confirm that the downregulation of FOXO1 was not caused by chemotherapeutic treatment, the mRNA or protein level was detected following chemotherapeutic treatment. (C) p21 expression level following chemotherapeutic treatment. (D) ChIP assay, revealing the binding activity of FOXO1 to the p21 promoter region. " $\mathrm{P}<0.05$, compared with mock. miR-96, microRNA-96; FOXO1, forkhead box protein O1; ChIP, chromatin immunoprecipitation; shRNA, short hairpin RNA; Ab, antibody; UTR, untranslated region; p21, cyclin-dependent kinase inhibitor 1A; p53, tumor protein P53; PFT- $\alpha$, Pifithrin- $\alpha$. 
A

\section{Cisplatin}

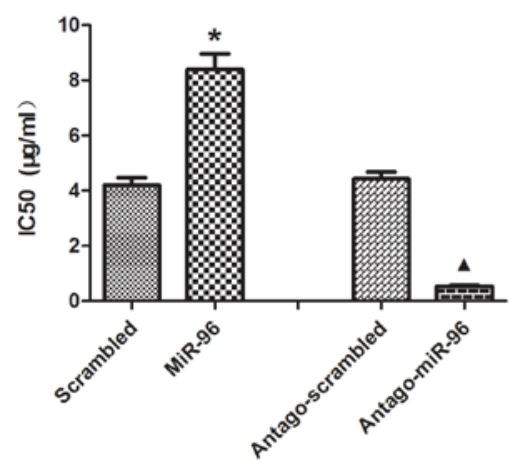

B
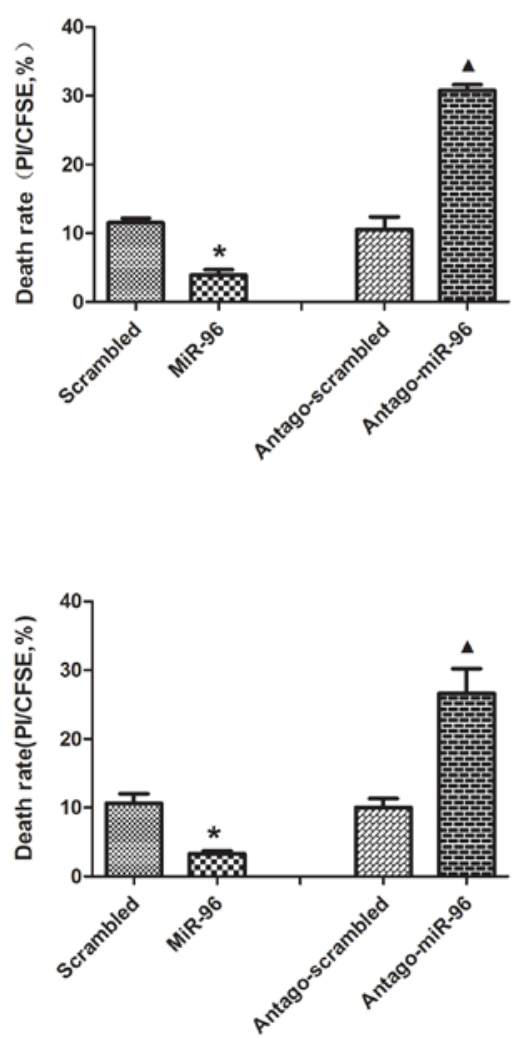

Doxorubicin

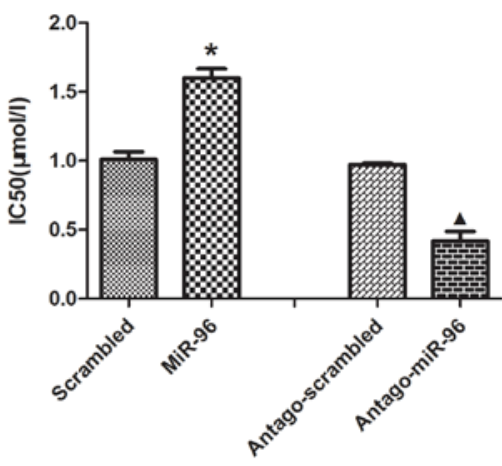

Cisplatin

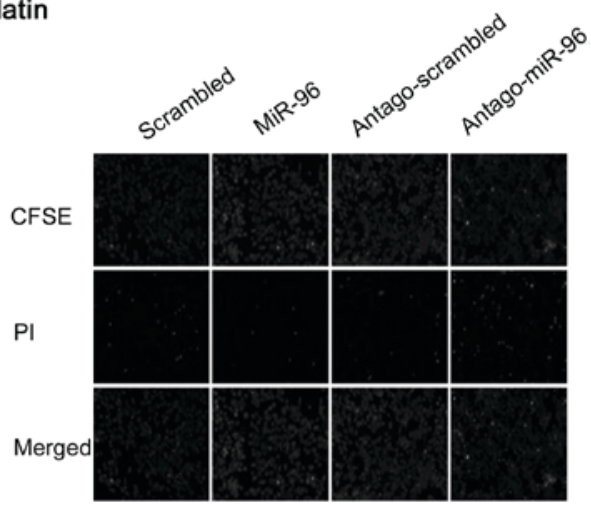

Doxorubicin

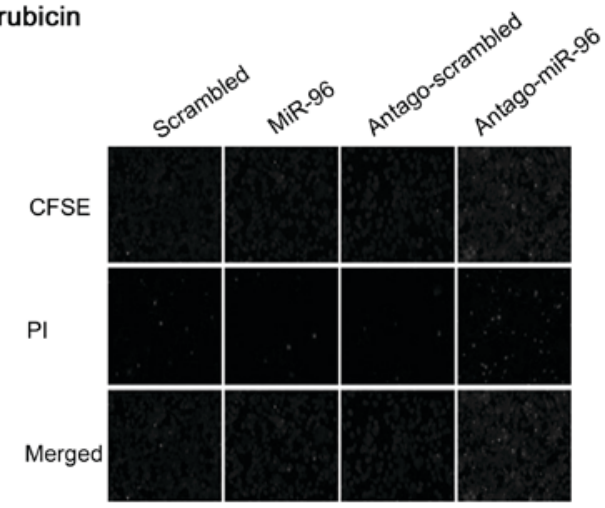

Figure 3. Expression of miR-96 induced the chemoresistance in SGC7901 cells. (A) The $\mathrm{IC}_{50}$ of cisplatin and doxorubicin following transfection. (B) The cell death rate was analyzed by CFSE/PI double-staining (right) and flow cytometry (left), respectively. ${ }^{*} \mathrm{P}<0.05$, compared with scrambled; ${ }^{\mathbf{}} \mathrm{P}<0.05$, compared with Antago-scrambled. $\mathrm{IC}_{50}$, half-maximal inhibitory concentration; CFSE, carboxyfluorescein succinimidyl ester; PI, propidium iodide.

Overexpression of miR-96 induces the chemoresistance and decreased the death rate following chemotherapeutic treatment. As expected, overexpression of miR-96 in SGC7901 increased the half-maximal inhibitory concentration $\left(\mathrm{IC}_{50}\right)$ of cisplatin and doxorubicin. The repression of miR-96 upon treatment with antago-miR-96 significantly increased the chemosensitivity of SGC7901 (Fig. 3A). The results of CFSE/PI revealed that SGC7901 cells transfected with exogenous miR-96 exhibited fewer PI-positive cells and SGC7901 cells transfected with antago-miR-96 exhibited much more PI positive cells by compared with their control group (Fig. 3B, right). The results of the flow cytometry assay confirmed that overexpression of miR-96 is critical for decreasing the cell death rate of SGC7901 cells (Fig. 3B, left).

miR-96 promotes proliferation of SGC7901. According to previous results, overexpression of miR-96 possibly affects cell proliferation by regulating p21 (21). The results of the CCK-8 assay revealed that, miR-96 overexpression promoted the proliferation of SGC7901, and conversely, treatment with antago-miR-96 significantly inhibited proliferation (Fig. 4, left panel). Similar results were obtained from the EdU staining assay, which was further performed for confirming this observation (Fig. 4, right panel). 



Figure 4. Expression of miR-96 promoted cell proliferation in SGC7901 cells. Cell Counting kit-8 assays performed following chemotherapeutic treatment (left) and the EdU staining assay (right) are depicted. " $\mathrm{P}<0.05$, compared with scrambled; ${ }^{\mathbf{\Delta}} \mathrm{P}<0.05$, compared with Antago-scrambled. miR-96, microRNA-96; OD, optical density; EdU, 5-ethynyl-2'-deoxyuridine.

\section{Discussion}

Chemotherapy is the most widely used therapeutic strategy for cancer treatment besides surgery (21). However, drug resistance, particularly multidrug resistance, greatly limits its clinical use. Changes in miRNA expression levels have been found to contribute to multiple cancer-associated processes, including initiation, progression and chemoresistance (22). The association between the expression level of miRNAs and cancer has indicated that changes to miRNA expression profiles may be associated with responses to the treatment of patients with chemotherapeutic agents. Therefore, further research on the miRNAs whose expression is altered by chemotherapy is required.

The present study revealed that miR-96 expression was positively induced by chemotherapeutic treatment at certain doses, which post-transcriptionally repressed the expression of FOXO1 and thus led to the inhibition of p21 transcription, which is a FOXO1-target gene in gastric cancer cells. These results indicated that miR-96 could function as a promoter of chemoresistance by promoting cell proliferation in gastric cancer cells. To the best of our knowledge, the present study is the first to investigate the association between miR-96 and chemotherapy in gastric cancer cells. In the previous reports, miR-96 has a critical role in various types of tumor. Yu et al (12) revealed that in pancreatic cancer cells, miR-96 repressed expression of the oncogene KRAS by directly targeting its mRNA, thus functioning as a tumor-suppressor miRNA and causing a decrease in proliferation, invasion, migration and tumor growth. Vishwamitra et al (23) revealed that the heterogeneous expression of miR-96 in lymphoma kinase-expressing cancer cells decreased the proliferation, colony formation, and migration of cells via a posttranscriptional regulatory mechanism. Contrarily, miR-96 has also been shown to function as a tumor-promoting miRNA by increasing the proliferation, migration, and invasion of various different types of cancer cell, including breast cancer (24). In hepatocellular carcinoma cells (HCC), induction of miR-96 expression promotes the invasion of HCC cells, indicating that miR-96 may be a therapeutic target for inhibiting HCC metastasis (25).

FOXO1, reported to be a downstream mediator of CPT-triggered apoptosis $(26,27)$, is phosphorylated by CDK1 and protein kinase B (AKT), and thus be activated as a transcriptional regulator on its target gene, p21 (20). FOXO1 is transcriptionally regulated by several mechanisms, aforementioned, including AKT signaling. The present study confirmed that FOXO1 mRNA was bound by miR-96 in gastric cancer cells. Consequently, the specific binding of miR-96 to FOXO1 mRNA markedly downregulated the protein level and caused the alteration of phenotype in SGC7901.

In summary, the characterization of miR-96 identified that it was a novel inducer of cell proliferation, migration, invasion and tumor formation following chemotherapeutic treatment of gastric cancer cells. The oncogenic function of miR-96 is in part explained by its inhibition of FOXO1. The results of the present study indicate that functional FOXO1 could be considered as a biomarker for processing chemotherapy and miR-96 could be considered as a novel target for reversing chemoresistance in gastric cancer. 


\section{Acknowledgements}

Not applicable.

\section{Funding}

No funding was received.

\section{Availability of data and materials}

All data generated or analyzed during this study are included in this published article.

\section{Authors' contributions}

CL designed the study and was a major contributor in writing and revising the manuscript. MX performed the cell culture, analyzed and interpreted the data. $\mathrm{ZZ}$ performed the reverse transcription-quantitative polymerase chain reaction and other molecular biology experiments and revised the manuscript. JC and LZ made substantial contribution to designing this study and revised the manuscript. All authors read and approved the final manuscript.

\section{Ethics approval and consent to publish}

Not applicable.

\section{Consent for publication}

Not applicable.

\section{Competing interests}

The authors declare that they have no competing interests.

\section{References}

1. Lagos-Quintana M, Rauhut R, Lendeckel W and Tuschl T: Identification of novel genes coding for small expressed RNAs Science 294: 853-858, 2001.

2. Filipowicz W, Bhattacharyya SN and Sonenberg N: Mechanisms of post-transcriptional regulation by microRNAs: Are the answers in sight? Nat Rev Genet 9: 102-114, 2008.

3. Esquela-Kerscher A and Slack FJ: Oncomirs-microRNAs with a role in cancer. Nat Rev Cancer 6: 259-269, 2006.

4. Wu CW, Hsiung CA, Lo SS, Hsieh MC, Chen JH, Li AF, Lui WY and Whang-Peng J: Nodal dissection for patients with gastric cancer: A randomised controlled trial. Lancet Oncol 7: 309-315, 2006.

5. Sharma MR and Schilsky RL: GI cancers in 2010: New standards and a predictive biomarker for adjuvant therapy. Nat Rev Clin Oncol 8: 70-72, 2011.

6. Smyth EC and Cunningham D: Gastric cancer in 2012: Defining treatment standards and novel insights into disease biology. Nat Rev Clin Oncol 10: 73-74, 2013.

7. Dassen AE, Lemmens VE, van de Poll-Franse LV, Creemers GJ, Brenninkmeijer SJ, Lips DJ, Vd Wurff AA, Bosscha K and Coebergh JW: Trends in incidence, treatment and survival of gastric adenocarcinoma between 1990 and 2007: A population-based study in the Netherlands. Eur J Cancer 46: 1101-1110, 2010.
8. GASTRIC (Global Advanced/Adjuvant Stomach Tumor Research International Collaboration) Group, Oba K, Paoletti X, Bang YJ, Bleiberg H, Burzykowski T, Fuse N, Michiels S, Morita S, Ohashi Y, et al: Role of chemotherapy for advanced/recurrent gastric cancer: An individual-patient-data meta-analysis. Eur J Cancer 49: 1565-1577, 2013.

9. Wang TH, Yeh CT, Ho JY, Ng KF and Chen TC: OncomiR miR-96 and miR-182 promote cell proliferation and invasion through targeting ephrinA5 in hepatocellular carcinoma. Mol Carcinog 55: 366-375, 2016.

10. Zhang J, Kong X, Li J, Luo Q, Li X, Shen L, Chen L and Fang L: miR-96 promotes tumor proliferation and invasion by targeting RECK in breast cancer. Oncol Rep 31: 1357-1363, 2014.

11. Guo H, Li Q, Li W, Zheng T, Zhao S and Liu Z: MiR-96 downregulates RECK to promote growth and motility of non-small cell lung cancer cells. Mol Cell Biochem 390: 155-160, 2014.

12. Yu S, Lu Z, Liu C, Meng Y, Ma Y, Zhao W, Liu J, Yu J and Chen J: miRNA-96 suppresses KRAS and functions as a tumor suppressor gene in pancreatic cancer. Cancer Res 70: 6015-6025, 2010.

13. Wang Y, Luo H, Li Y, Chen T, Wu S and Yang L: hsa-miR-96 up-regulates MAP4K1 and IRS1 and may function as a promising diagnostic marker in human bladder urothelial carcinomas. Mol Med Rep 5: 260-265, 2012.

14. Wu L, Pu X, Wang Q, Cao J, Xu F, Xu LI and Li K: miR-96 induces cisplatin chemoresistance in non-small cell lung cancer cells by downregulating SAMD9. Oncol Lett 11: 945-952, 2016.

15. Lin H, Dai T, Xiong H, Zhao X, Chen X, Yu C, Li J, Wang X and Song L: Unregulated miR-96 induces cell proliferation in human breast cancer by downregulating transcriptional factor FOXO3a. PLoS One 5: e15797, 2010.

16. Haflidadóttir BS, Larne O, Martin M, Persson M, Edsjö A, Bjartell A and Ceder Y: Upregulation of miR-96 enhances cellular proliferation of prostate cancer cells through FOXO1. PLoS One 8: e72400, 2013.

17. Bazzoni F, Rossato M, Fabbri M, Gaudiosi D, Mirolo M, Mori L, Tamassia N, Mantovani A, Cassatella MA and Locati M: Induction and regulatory function of miR-9 in human monocytes and neutrophils exposed to proinflammatory signals. Proc Natl Acad Sci USA 106: 5282-5287, 2009.

18. Livak KJ and Schmittgen TD: Analysis of relative gene expression data using real-time quantitative PCR and the 2(-Delta Delta C(T)) method. Methods 25: 402-408, 2001.

19. Xie XQ, Zhao QH, Wang H and Gu KS: Dysregulation of mRNA profile in cisplatin-resistant gastric cancer cell line SGC7901. World J Gastroenterol 23: 1189-1202, 2017.

20. Machida S, Spangenburg EE and Booth FW: Forkhead transcription factor FoxO1 transduces insulin-like growth factor's signal to p27Kip1 in primary skeletal muscle satellite cells. J Cell Physiol 196: 523-531, 2003.

21. Wu Z, Liu K, Wang Y, Xu Z, Meng J and Gu S: Upregulation of microRNA-96 and its oncogenic functions by targeting CDKN1A in bladder cancer. Cancer Cell Int 15: 107, 2015.

22. Zhang XL, Shi HJ, Wang JP, Tang HS, Wu YB, Fang ZY, Cui SZ and Wang LT: MicroRNA-218 is upregulated in gastric cancer after cytoreductive surgery and hyperthermic intraperitoneal chemotherapy and increases chemosensitivity to cisplatin. World J Gastroenterol 20: 11347-11355, 2014.

23. Vishwamitra D, Li Y, Wilson D, Manshouri R, Curry CV, Shi B, Tang XM, Sheehan AM, Wistuba II, Shi P and Amin HM: MicroRNA 96 is a post-transcriptional suppressor of anaplastic lymphoma kinase expression. Am J Pathol 180: 1772-1780, 2012.

24. Hong Y, Liang H, Uzair-Ur-Rehman, Wang Y, Zhang W, Zhou Y, Chen S, Yu M, Cui S, Liu M, et al: miR-96 promotes cell proliferation, migration and invasion by targeting PTPN9 in breast cancer. Sci Rep 6: 37421, 2016.

25. Chen RX, Xia YH, Xue TC and Ye SL: Suppression of microRNA-96 expression inhibits the invasion of hepatocellular carcinoma cells. Mol Med Rep 5: 800-804, 2012.

26. Han S and Wei W: Camptothecin induces apoptosis of human retinoblastoma cells via activation of FOXO1. Curr Eye Res 36: 71-77, 2011.

27. Huang H, Regan KM, Lou Z, Chen J and Tindall DJ: CDK2-dependent phosphorylation of FOXO1 as an apoptotic response to DNA damage. Science 314: 294-297, 2006. 